\title{
Análisis de las estrategias docentes para promover la convivencia y disciplina en el nivel de educación preescolar
}

\author{
MARÍA CONCEPCIÓN CHÁVEZ ROMO* \\ Universidad Pedagógica Nacional

\section{AUREA RAMOS SÁNCHEZ $Z^{*}$ PAOLA ZUGEY VELÁZQUEZ JARAMILLO"*s} \\ Secretaría de Educación Pública. Nivel Preescolar \\ Recibido el 05-03-2016; primera evaluación el 10-04-2017; \\ segunda evaluación el 25-04-2017; aceptado el 09-05-2017
}

\section{Resumen}

Se exponen las estrategias construidas por docentes de educación preescolar de México para afrontar retos de la convivencia y la disciplina en el aula. Las estrategias mencionadas fueron clasificarlas en tres grupos: de contención, pedagógicas, y de atención especializada y psicológica. Algunas de las entrevistadas señalan que su empleo sistemático contribuye a la reducción de conductas disruptivas o eventos de indisciplina en el aula; otras manifiestan incertidumbre frente a los resultados de ahí que recurran al apoyo de especialistas. En esta contribución, además de

\footnotetext{
Profesora en la Universidad Pedagógica Nacional. Doctora en Pedagogía por la Universidad Nacional Autónoma de México (UNAM). Miembro de la Red Nacional de Investigadores en Educación y Valores, A.C (REDUVAL). Especialista en procesos de formación docente y desarrollo de investigaciones educativas en temas de ciudadanía, derechos humanos y valores. Contacto: cchavezr@g.upn.mx

** Docente en el nivel de educación preescolar. Egresada de la Escuela Nacional para Maestras de Jardines de Niños. Exasesora externa en la Dirección de Actualización y Centros de Maestros. Pasante de la Maestría en Educación Básica, Especialidad en Gestión de la Convivencia en la Escuela, Violencia, Derechos Humanos y Cultura de Paz, por la Universidad Pedagógica Nacional unidad 094. Contacto: aurea.ramos24@yahoo.com.mx

${ }^{* * *}$ Docente en el nivel de educación preescolar. Egresada de la Escuela Nacional para Maestras de Jardín de Niños. Con estudios en Especialización de gestión de la convivencia, violencia, derechos humanos y cultura de paz, en la Universidad Pedagógica Nacional unidad 097. Estudiante de la Maestría en Desarrollo Educativo en la Línea de Prácticas Institucionales y Formación Docente, en la Universidad Pedagógica Nacional unidad 092. Contacto: zugey2715@hotmail.com
} 
describir el conjunto de estrategias encontradas, se analiza si mediante estas acciones es factible impulsar procesos de aprendizaje donde los niños y niñas sean capaces de regular su conducta y ejercer su libertad con responsabilidad.

Palabras clave: Convivencia escolar, disciplina, violencia, educación preescolar

Analysis of educational strategies to promote coexistance and discipline at pre school level

\section{Abstract}

This work describes the strategies built by some teachers at pre school level in Mexico to face, from their perspective, coexistance and discipline challenges in the classroom. Given they variety of strategies mentioned, they were classified in three groups: restraining, pedagogical and of specialized and psycological care. Some of the interviewed teachers state that their systematic use contributes to the reduction of disruptive behaviors or misbehaving events in the classroom; other express uncertainty regarding the results and therefore they look for specialized suppot. In this contribution, in addition to describing the group of strategies found, we analyze if through these actions it is feasible to support learning processes in which children are capable to moderate their behavior and exercise their freedom responsibly.

Keywords: Coexistence school, discipline, violence, preschool education

\section{Análise de estratégias educativo para promover a convivência e disciplina no nível de pré-escolar}

\section{Resumo}

Este artigo discute as estratégias que têm construído alguns professores de nível pré-escolar no México para enfrentar, a partir de sua perspectiva, os desafios de convivência e disciplina em sala de aula são expostos. Dada a diversidade de estratégias mencionadas procedeu-se a classificá-los em três grupos: contençáo, educacionais e de aconselhamento especializado. Alguns dos entrevistados dizem que a sua utilização sistemática contribui para a redução de comportamentos ou eventos de indisciplina em sala de aula causadores de distúrbios; outros expressaram incerteza sobre os resultados, portanto, recorrer a apoio especializado. Nesta contribuição é também examina se essas ações é viável por impulsionar processo de aprendizagem onde as crianças são capazes de regular sua conduta e exercer a sua liberdade de forma responsável.

Palavras chave: vida escolar, disciplina, violência, pré-escolar 


\section{INTRODUCCIÓN}

El análisis de la convivencia escolar y sus desafíos en la construcción de ambientes escolares inclusivos y democráticos probablemente no es una novedad para algunos países de América Latina, pero en México todavía son escasas las investigaciones educativas que documentan la diversidad de formas de gestionarla en escuelas de educación básica (preescolar, primaria y secundaria). Ante esta situación resulta clave considerar las aportaciones realizadas, en distintos ańos, por García y Vanella (1997) acerca de los valores, normas y estructuras de participación en el salón de clases y por Fierro y Carbajal (2003) sobre la oferta valoral de los docentes y sus tres senderos (comportamiento afectivo, normativo y la conducción de los aprendizajes). Fierro $\&$ Fortoul (2011) recuperan experiencias innovadoras desarrolladas en escuelas públicas del nivel básico en contextos vulnerabilizados. Otros estudios más recientes son los de Zurita (2011 y 2013) acerca de la situación actual de la legislación en materia de convivencia, seguridad y violencia escolar, así como el de Landeros y Chávez (2015) referido al análisis, desde la perspectiva de los derechos humanos, de los reglamentos escolares y de aula que norman la convivencia en escuelas de educación básica.

En otra línea de generación de conocimiento se encuentran las reflexiones de Yurén (2005) sobre los modos en que se adquieren los saberes existenciales y sociomorales (ambos saberes están íntimamente relacionados con aprender a convivir y a ser persona), así como el estudio de Latapí (2003) sobre las propuestas educativas para formar en valores y sus métodos de aprendizaje.

Mención especial merece el último estado del conocimiento elaborado por miembros del Consejo Mexicano de Investigación Educativa (COMIE, 2013) correspondiente a los ańos 2002-2011 donde se identifican dos tendencias de estudio en materia de disciplina y convivencia escolar; por un lado, el enfoque normativo-prescriptivo, integrado por dos vertientes: 1) Convivencia como prevención de la violencia, 2) Convivencia como parte de la calidad de la educación y condición básica para el logro académico; y por el otro, se encuentran aquellos estudios ubicados en el enfoque analítico, donde el abordaje de la convivencia tiene la intención de comprender e interpretar el sentido de las relaciones y la experiencia subjetiva de los involucrados en el proceso educativo (Fierro \& Tapia, 2013). En este mismo informe, se muestra que en la mayoría de las investigaciones educativas mexicanas, generadas en la última década, se le ha dado prioridad a la comprensión de la violencia escolar entre pares (bullying y acoso escolar) y dejado al margen otros aspectos y actores 
clave que interactúan con los alumnos; esta es una razón más para aproximarnos a la comprensión de los desafíos de la convivencia escolar, a partir de las voces de un grupo de educadoras.

Por último, conviene advertir el escaso análisis de lo que sucede en las escuelas de educación preescolar. Tanto en los trabajos reportados en el actual estado del conocimiento en materia de Convivencia escolar como Disciplina e indisciplina en la escuela, sobresalen las investigaciones que se centran en el nivel de educación primaria y secundaria (Fierro \& Lizardi, 2013; Pereda, Plá \& Osorio, 2013). Indiscutiblemente esta situación de escasez de estudios, de alguna manera, repercute en los procesos de intervención educativa porque al tratar de brindar apoyos concretos a las educadoras del nivel preescolar para gestionar la convivencia, frecuentemente se retoman reflexiones dirigidas a otros niveles educativos y, a partir de ellas, se generan propuestas de intervención basadas en un deber ser distante de las realidades de los jardines de niños. Esta situación exhibe que, en pleno siglo XXI, el reto de aprender a vivir juntos persiste no solo como un desafío educativo sino también como línea de generación de conocimiento estratégica para comprender la diversidad de asuntos que se debaten en las instituciones escolares y definir alternativas innovadoras para introducir otras formas de gestionar la convivencia.

En este trabajo se comparten algunos resultados derivados de un proyecto de investigación más amplio, y en curso, titulado Los desafíos de la convivencia en las escuelas de educación básica desde la perspectiva de los derechos humanos y la cultura de paz: concepciones, prácticas y estrategias, cuyo propósito general es contribuir a la comprensión del fenómeno. En esta ocasión solamente se hará referencia a las estrategias que emplean las docentes en el nivel de educación preescolar para afrontar desafíos de la convivencia en su grupo.

Para fines analíticos se incorpora el enfoque de los derechos humanos como un componente ético que permite valorar lo que ocurre en la convivencia en las escuelas desde un lugar específico donde cobran relevancia las experiencias de participación y solidaridad para el desarrollo de la empatía.

Las reflexiones derivadas del estudio se presentan en tres apartados, el primero se reserva a la exposición de un conjunto de aspectos básicos de la convivencia como dimensión analítica; en el segundo se explica el procedimiento metodológico y la perspectiva de investigación. Posteriormente, en un tercer apartado se describen los tres tipos de estrategias identificadas y se cierra el artículo con una reflexión final. 


\section{REFERENTES TEÓRICO-CONCEPTUALES}

La Convivencia escolar como dimensión analítica de lo que acontece y se construye colectivamente en las instituciones escolares es útil, porque se relaciona con el proceso de construcción de ciudadanía que va más allá de los aprendizajes cívicos y éticos esperados en una asignatura o del tratamiento de temas transversales del currículo prescrito. Aprender a ser y aprender a vivir juntos (Delors, 1996) corresponden, de acuerdo con Yurén (2005) y Cortina (1996), al ámbito de los saberes prácticos, lo cuales se adquieren en la vivencia e interacción con otras personas y sin que medie una intencionalidad pedagógica propiamente dicha.

La convivencia escolar se refiere a sucesos espontáneos de la vida cotidiana (tensiones, divergencias y conflictos) en un espacio compartido por sujetos singulares pertenecientes a culturas diversas (Hirmas \& Eroles, 2008), así como a la interrelación entre los diferentes integrantes de una institución escolar (personal directivo, docentes, administrativos, alumnos, padres y madres de familia) con funciones y roles diferenciados (Perales, Arias \& Bazdresch, 2014). De modo general, podría señalarse que, a estos sujetos, los convoca el derecho a la educación, aunque con propósitos distintos, a unos, la responsabilidad ante los procesos de enseñanza y, a otros, el derecho a aprender (Tomasevski, 2004).

La adopción de los derechos humanos como punto de partida para valorar las acciones educativas que despliegan las docentes obliga a precisar qué aporta esta perspectiva en su componente ético a una educación para la convivencia. Siguiendo a Pérez Luño (1999), los derechos humanos son: «un conjunto de facultades e instituciones que, en cada momento histórico, concretan las exigencias de la dignidad, la libertad y la igualdad humanas, las cuales deben ser reconocidas positivamente por los ordenamientos jurídicos a nivel nacional e internacional» (p. 48).

Sin embargo su realización también requiere una sociedad donde sus integrantes, o al menos una mayoría de ellos, estén dispuestos a orientar sus acciones con base en principios como la igualdad en derechos y el respeto a la diversidad, la búsqueda de la equidad y la justicia, y la convivencia solidaria (Landeros \& Chávez, 2015). La escuela como institución pública cuyo propósito radica en la formación de ciudadanos tiene el deber de formar sujetos preferidores de estos principios. 
En este contexto cobra relevancia que el sistema educativo promueva, en los niveles de educación básica, experiencias significativas donde los niños tengan la oportunidad de reconocerse personas valiosas, dignas de un trato justo y respetuoso, capaces de gozar sus libertades fundamentales y ejercerlas responsablemente, así como ensayar formas de resolver los conflictos interpersonales que surgen en el contacto con sus pares. Es aquí donde adquiere mayor sentido conocer qué están haciendo los y las docentes en distintos niveles educativos para promover este tipo de aprendizajes. Por esta razón, después de conocer algunas estrategias que emplean las docentes del nivel de educación prescolar, conviene distinguir los modos de intervención más favorables desde una perspectiva educativa basada en los derechos humanos.

\section{AsPeCtOS METODOLÓgICOS Y PERSPECTIVA DE LA INVESTIGACIÓN}

Lo aquí se presenta deriva exclusivamente de la información proporcionada por catorce docentes que laboran en escuelas públicas de la Ciudad de México y sus resultados no pretenden ser representativos de ninguna zona escolar ni región del país. La muestra fue organizada conforme a los siguientes criterios de conveniencia: acesibilidad y disposición de las informantes para colaborar en el estudio, responder con amplitud a las preguntas planteadas y manifestar interés por el problema objeto de indagación. Las educadoras fueron entrevistadas entre los ańos 2014 y 2015. Todas ellas mujeres: nueve pertenecen a diferentes centros escolares y fueron contactadas en un Centro de Maestros al que acudían a eventos de actualización ${ }^{1}$; cinco son parte de la planta docente de un jardín de niños ${ }^{2}$. En el siguiente cuadro se muestran algunos datos de su ejercicio profesional.

\footnotetext{
1 Estas educadoras fueron entrevistadas por Aurea Ramos Sánchez, quien en su tesis de maestría profundiza en las necesidades de profesionalización y actualización docente en el nivel de educación preescolar.

2 Las entrevistas fueron realizadas por Paola Zugey Velázquez Jaramillo, estudiante de la Maestría en Desarrollo Educativo cuya tesis se centra en el análisis de las estrategias que emplean las educadoras para el conservar orden y la disciplina en el salón de clases.
} 
Tabla 1. Datos del ejercicio profesional de la muestra

\begin{tabular}{llll}
\hline \multicolumn{1}{c}{ Nivel educativo } & \multicolumn{1}{c}{ Estudios } & \multicolumn{1}{c}{$\begin{array}{c}\text { Grado que } \\
\text { imparte }\end{array}$} & \multicolumn{1}{c}{$\begin{array}{c}\text { Delegación donde } \\
\text { trabajan }\end{array}$} \\
\hline $\begin{array}{l}\text { Preescolar } \\
\begin{array}{l}\text { Educadoras de preescolar } \\
\text { entrevistadas en Centros de } \\
\text { Actualización al Magisterio }\end{array}\end{array}$ & $\begin{array}{l}\text { Licenciatura } \\
\text { en educación } \\
\text { preescolar }\end{array}$ & $\begin{array}{l}5 \text { de segundo } \\
\text { grado }\end{array}$ & $\begin{array}{l}4 \text { en Álvaro Obregón } \\
\text { 3 en Iztacalco }\end{array}$ \\
\hline $\begin{array}{l}\text { Educadoras pertenecientes a } \\
\text { un jardín de niños }\end{array}$ & $\begin{array}{l}\text { Licenciatura } \\
\text { en educación } \\
\text { preescolar }\end{array}$ & $\begin{array}{l}5 \text { educadoras } \\
\text { (cubren los tres } \\
\text { grados) }\end{array}$ & $\begin{array}{l}\text { Escuela ubicada en } \\
\text { la Delegación Álvaro } \\
\text { Obregón }\end{array}$ \\
\hline
\end{tabular}

Sus edades son diversas de modo que no es posible señalar una edad promedio, se encuentran entre los 35 y 50 años de edad y, por tanto los ańos en el ejercicio profesional también son variables; hay quienes tienen 4, 10, 15 o 20 frente a grupo y otras cuentan con 30 ańos de experiencia.

Se trata de una investigación cualitativa, ubicada en el paradigma de las ciencias simbólicas que concibe lo social "como una realidad que se crea y se mantiene a través de interacciones simbólicas y pautas de comportamiento" (Popkewitz, 1988, p. 71) de ahí su carácter interpretativo. En los estudios de corte cualitativo, interesa sistematizar y analizar los sentidos y significados que los sujetos les otorgan a sus actos y descubrir la lógica que subyace en sus relaciones con los demás (con los otros). Asimismo, se le da prioridad a la descripción y comprensión de las acciones de los sujetos en un contexto específico. Desde esta perspectiva, la entrevista se concibe como una interacción social que produce una comunicación de significados: una persona expone su particular visión de un problema y la otra procura comprender e interpretar dicha explicación (Rodríguez, 1999). Es una herramienta flexible, dinámica, no estandarizada, donde se producen, de acuerdo con Taylor y Bogdan (1987): «reiterados encuentros cara a cara entre el investigador y los informantes, encuentros estos dirigidos hacia la comprensión de las perspectivas que tienen los informantes respecto de sus vidas, experiencias o situaciones, tal como las expresan con sus propias palabras» (p.101).

Para encontrarle sentido a la información recabada se procedió de modo inductivo-deductivo; del ordenamiento conceptual a la interpretación y generación de datos significativos (Coffey \& Atkinson, 2003).

A continuación se presenta el guión general de la investigación que dio lugar a las entrevistas. 
Tabla 2. Guion general de la investigación

\begin{tabular}{ll}
\hline \multicolumn{1}{c}{ Aspecto o dimensión } & \multicolumn{1}{c}{ Preguntas específicas } \\
\hline Sobre la escuela & - ¿Cuáles son los problemas o retos de la convivencia en su \\
& escuela? \\
& ¿Por qué se originan? \\
& - ¿Qué hacen en la escuela para enfrentarlos?, ¿qué estrategias \\
& emplean? \\
& - ¿Qué tipo de apoyo reciben de parte de la Secretaría de \\
& Educación Publica?, ¿de qué otras instituciones han recibido \\
& apoyo? (Señale cursos o eventos diversos que recuerde y que \\
& se relacionan con el tema), ¿les han ayudado para gestionar la \\
& convivencia en su escuela? \\
\hline Sobre su grupo o grupo & - ¿Cuáles son los problemas o retos de la convivencia en los \\
de escolares & grupos que usted imparte clases? \\
& - ¿En qué situaciones surgen más problemas de convivencia? \\
& - ¿Quiénes son los principales protagonistas? \\
& ¿Qué hace usted para enfrentarlos? \\
& ¿Qué estrategias emplea? \\
& ¿Cuáles considera que funcionan mejor?, ¿por qué? \\
& ¿Cuáles han sido las dificultades a las que se ha enfrentado al \\
promover la convivencia en su grupo?
\end{tabular}

A lo largo del escrito se incorporan fragmentos de las narraciones de las docentes a las que se les asignó una clave integrada por la inicial del nombre de la entrevistadora, el año en que se realizó y el número de la entrevista a la que se hace referencia, quedando de la siguiente manera: A2014E\#4.

\section{Estrategias Para AFrontar los desafíos de la CONVIVENCia EN EL SALÓN DE CLASES}

Las estrategias que a continuación se presentan no se reducen al orden de lo didáctico; en un sentido más amplio corresponden a un conjunto de acciones de diversa naturaleza empleadas para responder a eventos que surgen en la dinámica de trabajo en el aula y en las relaciones interpersonales entre alumnos. En este sentido, se entiende por estrategias aquellos procedimientos, técnicas y actividades dirigidos hacia un objetivo específico (Monereo, 1994), sin ser exclusivo del ámbito de la planeación didáctica. Además, como se mos- 
trará adelante, en la práctica docente no siempre forman parte de un plan diseñado deliberadamente.

La clasificación de las estrategias está inspirada en un material de la Serie convivencia escolar (Fierro, Carbajal \& Martínez-Parente, 2010) producido por la Red Latinoamericana de Convivencia Escolar en el que, a partir de los aportes de Bickmore (2004), describen tres tipos de estrategias: de contención, formación y transformación. Debido a las características de las acciones y formas de proceder que narran las educadoras, en este caso, fue necesario realizar ajustes a la denominación de las dos últimas. Así se obtuvo tres tipos: las de contención, las pedagógicas, y las de atención especializada y psicológica.

El primer tipo se ha definido como estrategias de contención por considerarse modos de responder para poner un alto al problema surgido, sea en el salón de clases o en otro espacio escolar. Frecuentemente tienen una influencia restringida al momento en que ocurre el evento. Un segundo tipo corresponde a estrategias pedagógicas por su intencionalidad formativa claramente explícita; con su puesta en marcha se busca generar nuevas formas de relación, aunque en ciertas ocasiones su incidencia se vea limitada por dos razones:

1. Las acciones docentes se centran en la prescripción de valores y pautas de comportamiento quedando al margen los procesos de reflexión y diálogo para que los niños se introduzcan en el descubrimiento gradual del otro y el desarrollo de la empatía.

2. Su abordaje omite al grupo y se enfoca la atención en el protagonista central de la disrupción, indisciplina o evento de violencia. De esta manera, se interpreta el hecho suscitado como un asunto individual cuyo origen se encuentra en el sujeto.

El tercer tipo surge cuando las educadoras consideran que ya no pueden atender el caso exclusivamente desde su quehacer pedagógico. De esta manera, la búsqueda de asesoría especializada aparece como el último eslabón en la cadena de estrategias construidas; por eso se han denominado estrategias de atención especializada y psicológica. En la tabla que se presenta a continuación, estas últimas forman parte de la solicitud y búsqueda de apoyo.

La distribución y organización visual de las estrategias busca evidenciar que, muchas veces, estas son complementarias o se convierten en un peldaño previo de la siguiente. 


\section{Tabla 3. Conjunto de estrategias para afrontar desafíos de la convivencia y disciplina}

\begin{tabular}{|c|c|c|}
\hline Estrategias de contención & Estrategias pedagógicas & $\begin{array}{l}\text { Estrategias de } \\
\text { atención especiali- } \\
\text { zada y psicológica }\end{array}$ \\
\hline $\begin{array}{l}\text { 1. Les llaman la aten- } \\
\text { ción, los exhortan. } \\
\text { 2. Recuerdan o aplican el } \\
\text { reglamento de aula (pres- } \\
\text { cripción y amenazas). } \\
\text { 3. El cambio de lugar: } \\
\text { una práctica cotidiana } \\
\text { frente a casos específicos. } \\
\text { 4. El cambio de grupo o } \\
\text { traslado a la dirección. } \\
\text { 5. Mantener al grupo } \\
\text { realizando actividades, } \\
\text { "tenerlos ocupados". }\end{array}$ & $\begin{array}{l}\text { 1. Hablan con ellos e indagan sobre el } \\
\text { problema. } \\
\text { 2. Aplican estrategias específicas como la revi- } \\
\text { sión o elaboración colectiva del reglamento } \\
\text { de aula, el semáforo de la conducta, la técnica } \\
\text { del adiós, entre otras. } \\
\text { 3. Promueven el trabajo colaborativo y la } \\
\text { pertenencia a diferentes equipos. } \\
\text { 4. Solicitan y buscan diversos tipos de apoyo. } \\
\text { a) Se informa a los padres y madres de familia } \\
\text { o tutores para que apoyen el trabajo escolar. } \\
\text { b) Consultan y solicitan apoyo a compañeras } \\
\text { docentes }\end{array}$ & $\begin{array}{l}\text { c) Solicitan y } \\
\text { buscan apoyo de } \\
\text { especialistas. }\end{array}$ \\
\hline
\end{tabular}

Fuente: Elaboración de las autoras derivada de la clasificación de las acciones y procedimientos narrados por las entrevistadas.

\subsection{Estrategias de contención}

Les llaman la atención, los exhortan. Frente a situaciones específicas les señalan a los niños la falta cometida, los invitan a comportarse de otra manera y les advierten que no son válidas ciertas actitudes o formas de relacionarse con sus pares. Sirva de muestra el siguiente fragmento.

Aaah, pues los llamo a los dos y les digo: a ver ¿a ti, te gustaría que te hicieran lo mismo?, no ¿iverdad? Entonces, te voy a pedir que no lo vuelvas a hacer porque eso no está bien, y si a ti no te gusta que te molesten pues no hagas lo mismo para que a ti te respeten, recuerda que el respeto es importante para poder convivir y eso es lo que venimos a hacer aquí en la escuela. ¿A ver, tú ves que yo actúo así con mis compañeras maestras?, ¿̇verdad que no?, entonces por favor no quiero que vuelva a ocurrir, así que se dan la mano y no vuelvan a pelear" y pues así se soluciona el problema en ese momento (A2014E\#2).

Se emplea la exhortación y el regaño como métodos que pueden producir algún cambio en ciertos comportamientos de los niños y niñas. En otros casos, el señalamiento de que serán rechazados por sus pares, también funciona para contener; por ejemplo, se le dice al niño que si se sigue portando mal sus compańeros no lo van a querer como integrante de su equipo. 
Recuerdan o aplican el reglamento de aula. Guarda similitud con lo ya expuesto, la diferencia radica en que la exhortación se respalda en la alusión a una norma específica incluida en el reglamento.

El cambio de lugar: una práctica cotidiana frente a casos especificos. Es frecuente que en los grupos de escolares exista alguien que molesta o violenta de modo constante a otros niños y niñas.

En la escuela es lo que hago con el niño hablar con él, ¿por qué hiciste eso?, entonces, ya ellos me argumentan: no es que me quitó [...]. Yo llamo a los dos y les digo 'por qué hizo esto' ya empiezan a dialogar entre ellos [...], cuando vienen conmigo es porque 'ya me pegó' me avisan y no dicen yo hice esto, ellos dicen 'me hicieron', mas no reconocen que ellos también están haciendo. Esa es una de las formas como trabajo: platicar y separarlos, no es conveniente que estén juntos porque se están molestando o cambio de lugar a los chicos y seguimos trabajando (P2015E\#3).

Como primera fase de la estrategia se hace uso del diálogo y la exhortación; asimismo, se les pide a los protagonistas de las acciones violentas que se disculpen con el afectado. Después se procede a reubicarlos en el salón de clases.

La mayoría de las docentes sientan al niño o niña cerca de ellas para observar su comportamiento y evitar el surgimiento de otros problemas, como son: las quejas de parte de los familiares de los nińos agredidos. Si bien, este tipo de medidas permite avanzar en el desarrollo de las actividades de aprendizaje y logra resolver momentáneamente la situación, es improbable que dicha práctica de aislamiento del grupo contribuya a la resolución del problema. La separación del grupo significa evitar el contacto del grupo con el nińo y a él, impedirle la interacción con sus compañeros. De esta manera, se afianza el distanciamiento y obstaculiza que el niño aprenda a relacionarse de otro modo con sus compañeros y compañeras.

La segunda fase de esta estrategia es precisamente mantenerlos a la vista y solicitar el apoyo de la mamá o de algún otro miembro de la familia ${ }^{3}$ para proporcionar una atención individualizada.

En ciertas ocasiones se realiza un trabajo personalizado y extraclase.

Hablando directamente con las mamás, explicándoles la situación desde cómo se comportan en la escuela, invitándolas a trabajar fuera de horario de clases. Trabajo con ellos, de 15 a 20 minutos (A2014E\#6).

3 Queda pendiente revisar en qué medida esta estrategia contribuye a la exacerbación o consolidación de las actitudes que se quieren disminuir, así como a la estigmatización del excluido. 
En otros casos se invita a la mamá o a la persona que funja como tutora del niño para que acuda al salón y pueda observar su forma de relacionarse y desempeño escolar.

En situaciones específicas con ellos, están presentes las mamás con los niños para que vean cómo trabajamos, y vean en qué momento se salen, pierden la atención, para que ellas se den cuenta y no que nada más yo les cuente, sino que ellas también lo estén viviendo con los niños, y en base a lo que estemos trabajando ese día, les dejo tarea en casa y así cada día, o cada ocho días trabajo fuera del horario, también con la especialista de la escuela.

E. Y las mamás ¿qué comentarios te hacen?

R. Han respondido muy favorablemente, las cinco mamás que tengo [...] sí reconocen que en casa si les cuesta mucho trabajo, que no quieren hacer la tarea que se les deja. [Reconocen que] se les dificulta el manejo en casa, sobre todo una. La mamá de Alex. Ella sí me lo ha dicho así llorando, que no puede con su hijo, que sí le ha dado castigos muy fuertes [...]. El otro día Alex me dijo "es que mi mamá, nos encerró en el baño junto con mi hermano", entonces hablé con la señora, a ver señora ¿qué pasó?, me contó esto Alexander, la verdad sí, sí los encierro en el baño, porque me desespero. Entonces yo trato de guiarla, y decirle que no son adecuados esos castigos y que ella tiene que buscar otras estrategias y el otro día Alex llegó con un chipote chiquito pero sí se le veía y me contó que su mamá le aventó un cochecito y así, ese tipo de situaciones viven en casa (P2015E\#1).

El cambio de grupo o traslado a la dirección. En ambos casos implica permanecer marginado del grupo por un tiempo y no participar de las actividades colectivas. Una docente entrevistada narra el caso de un niño 'difícil de controlar' por una de sus colegas y que en un siguiente ciclo escolar le fue asignado. Este niño era llevado a veces a la dirección y en otras ocasiones se lo enviaban a ella. La educadora confiesa que, en ciertos momentos, no lo soportaba. Además, no recibía el apoyo de los papás. La directora decidió asignarlo a su grupo porque solamente con ella identificaba algunos cambios.

En las estrategias presentadas parece existir un particular interés por modelar una conducta y que los niños atiendan las reglas del aula. Al nińo se le advierte que no pertenecerá al grupo mientras no cumpla con las expectativas de sus compańeros y de la autoridad. Adicionalmente, la integración a otro grupo se asocia con castigo. Bajo esta lógica, si se logra tener éxito en la modificación de la conducta es muy probable que sea por temor y para evitar una situación que se experimenta como desagradable. En este sentido, habrá una menor violación a las normas, pero escaso aprendizaje sobre el sentido de responsabilidad (Curwin, Mendler \& Mendler, 2008). 
Mantener al grupo realizando actividades, "tenerlos ocupados". A diferencia de las anteriores estrategias, esta última involucra a todo el grupo y para ello se emplea, principalmente cantos y juegos. Es una solución que han encontrado las docentes para evitar fricciones en las relaciones interpersonales. No obstante, lejos de favorecer el reconocimiento de los conflictos y su abordaje lo que promueve es su evasión, a partir de limitar la producción de encuentros espontáneos.

\subsection{Estrategias pedagógicas}

Hablan con ellos e indagan sobre el problema. Como parte de los intentos de solución, las docentes platican con los involucrados en el incidente para conocer los motivos de la agresión y explicarles que los problemas se resuelven a través del diálogo o conversando y no a golpes. En otras ocasiones, se valen de recursos literarios y artísticos: narraciones de cuentos, cantos, rimas, juegos, trabalenguas, adivinanzas. Los destinatarios principales son aquellos pequeños a los que les cuesta trabajo "regular su conducta", expresar sus sentimientos sin golpes y son quienes protagonizan las divergencias. En este sentido, los esfuerzos por solucionar el problema se orientan al establecimiento de compromisos con el alumno. Este intento de solución también aparece documentado en otros estudios (Fierro, 2005, p. 1138).

Aplican técnicas de trabajo específicas. Como la revisión o elaboración colectiva del reglamento de aula, el semáforo de la conducta, la técnica del adiós y láminas de convivencia, entre otras.

Sobre la revisión o definición del reglamento de aula. Algunas docentes involucran a los niños en su elaboración, otras reconocen no hacerlo. Independientemente del procedimiento seguido, aquel sirve de referencia para invitarlos a convivir con respeto, sobre todo, cuando existe algún conflicto. Este modo de intervención asume un carácter restringido cuando omite la reflexión sobre la utilidad de las normas para la convivencia, o bien logra fungir como un verdadero dispositivo pedagógico si el reglamento de aula es producto de la construcción colectiva de pautas para relacionarse.

Yo tengo tres acuerdos muy importantes, que es, evito correr, evito empujar y evito gritar y de ahí por mes vamos trabajando otros de acuerdo a las necesidades del grupo. Por ejemplo, ahorita estamos trabajando el de levanto la mano para escucharme y para que los demás me escuchen, otro de los acuerdos que estamos manejando es comparto, y el último es todo somos amigos, y respetamos a los demás. Entonces, esos son los seis acuerdos básicos, y de ahí los niños van diciéndote qué hicieron, qué no hicieron, y en qué nivel se 
encuentran [...] Son capaces de decirte por ellos mismo en qué nivel están, del día o en la semana, casi lo hacemos diariamente o semanal. [...] ahorita ya también ellos son capaces de decirte en qué nos falta, por ejemplo, trabajar. Ahorita que retomamos el tema de la contaminación dicen que es importante que pongamos un acuerdo de tirar la basura en los botes o buscar un bote cuando no estás en la escuela o guardar la basura en tu bolsa hasta que llegues a casa y esto es otro de los acuerdos que estamos trabajando, utilizar la papelera para evitar la contaminación (P2015E\#4).

"El Semáforo de la conducta". Consiste en autoevaluar y coevaluar el comportamiento conforme a las reglas establecidas en el grupo. Varía su uso. Algunas educadoras ocupan esta técnica como inicio y cierre de las jornadas de trabajo y otras semanalmente.

El semáforo de la conducta tiene tres niveles, es como un semáforo vial, el nivel verde es que el nińo cumplió con todos los acuerdos, en el nivel amarillo los niños faltaron con alguno de los acuerdos, nivel rojo es donde los niños faltaron en la mayoría de los acuerdos, ellos mismo se van evaluado y [...] diciendo en qué nivel del semáforo se encuentran.

Al principio de la jornada de trabajo siempre recordamos, los acuerdos que tenemos en el aula, entonces vemos cómo esos acuerdos los tenemos que ir cumpliendo durante todas nuestras actividades del día y al final. Al principio yo les decía, mira cumpliste esto, esto no, ahora ya ellos mismos dicen: bueno pues este yo grité o corrí en el salón, pero no empujé a mis compañeros (P2015E\#4).

"La técnica del adiós" es un ejemplo del cambio de grupo y se aplica cuando no se observa una modificación en la conducta del alumno. ¿En qué consiste? Se traslada al alumno a otro grupo bajo el supuesto de que, esto ayudará a que sea consciente de sus acciones y regule su conducta. Una educadora lo explica de la siguiente manera:

Arturo [...] muestra dificultad en seguir las reglas del salón [...] con él estoy emprendiendo la técnica que me sugirió la especialista de la escuela que es la técnica del "adiós" entonces si yo veo que Arturo se esté portando mal, que por ejemplo no sé, empezó a lanzar su suéter a sus compañeros y no hizo caso, bueno, entonces ya otra vez, Arturo, pero ahí fue adiós. Se llama tres veces [la atención] [...]. A la tercera se tiene que retirar del salón [...] pero a él le cuesta mucho trabajo, entonces es hablar con él, recordarle las reglas, las consecuencias, sobre todo eso hablar con él. Él se pone a llorar mucho, ya cuando es el tercer adiós, no lo soporta, no lo aguanta y es 'no, maestra, no maestra, ya me voy a comportar', y yo sé que, aunque a mí me duela, yo sé que si ya había esa indicación, pues con toda la pena, sí como que me cuesta mucho trabajo llevarlo, pero sé que tengo que hacerlo... (P2015E\#1). 
Nuevamente aquí aparece el aislamiento y exclusión del niño. La diferencia se encuentra en que se le incorpora a otro grupo que resulta desconocido para él.

[...] ya cuando regresa, de la otra maestra, que no han sido muchas, ya cuando regresa al salón, ya llega de diferente manera, y ya se pone a trabajar

-¿Por qué consideras que ha sido un logro?

Porque él se ha dado cuenta de las consecuencias [...], él se ha dado cuenta que al no seguir las reglas pues hay una consecuencia [...]. Un logro es que él siga ya las reglas del salón por ejemplo, y ya siguiendo las reglas del salón tiene más aprendizajes (P2015E\#1).

"Láminas de convivencia”. También incorporan los materiales educativos que son distribuidos por la Secretaría de Educación Pública derivados del Programa Nacional de Convivencia ${ }^{4}$. De manera específica, una educadora señaló las láminas de convivencia. Se trata de cuentos breves ilustrados acompañados de preguntas que favorecen la reflexión en torno a las acciones de los personajes.

Es un programa de la SEP, y lo tenemos que llevar acabo y además vienen unos libros también que son sobre la convivencia y por ejemplo "niños valientes" como que... a los niños se les están cuestionando mucho, qué opinan, qué harían, cómo lo resolverías, tú qué vas hacer, tú cómo te sientes, tú qué observas. (P2015E\#2).

"Atención individualizada". Se proporciona en aquellos casos donde los pequeños no logran realizar sus actividades por sí mismos. No obstante, las entrevistadas señalan que la cantidad de alumnos que integran sus grupos les impide brindar diariamente este tipo de servicio a quienes lo requieren.

Es necesario que se les explique de manera individual o simplemente estar a su lado para que realmente realicen las actividades solicitadas sin que estén molestando a los demás o peleando por los materiales, sin embargo, es algo que se dificulta por el número de nińos que se tiene en el grupo (A2014\#7).

...cuando escribe Omar y yo sé que dice eso pero no se le entiende y tengo un tercero, entonces bueno yo quisiera sentarme con ellos a trabajar individualmente pero no puedo qué hago con el resto del grupo? ( A2014E\#4).

\footnotetext{
4 Para mayor información ver Proyecto a Favor de la Convivencia Escolar (PACE) en línea http://basica.sep.gob.mx/convivencia/. Consiste en ofrecer materiales didácticos a los y las docentes para apoyar su trabajo.
} 
Promueven el trabajo colaborativo y la pertenencia a diferentes equipos. A lo largo del ciclo escolar, propician que niños y niñas se integren a diferentes grupos de trabajo porque, desde su perspectiva, la rotación y organización de los equipos con diferentes niños y niñas es clave para lograr cohesión grupal. Como estrategia complementaria, algunas educadoras distribuyen en los equipos a niños que se consideran más tranquilos y siguen sus indicaciones para que apoyen a sus compañeros en el desarrollo de las actividades encomendadas.

Aquellos niños que son más tranquilos y que siempre están atentos a las indicaciones que se les da para llevar a cabo las actividades para que apoyen a los pequeños, a los que se les dificulta centrar su atención y realizar sus actividades (A2014E\#6).

Las docentes aseguran que el trabajo entre pares apoya considerablemente la comprensión de los contenidos. Los niños a los que se les solicita un apoyo en especial acceden en primera instancia y tratan de apoyar a sus compañeros pero si se dan cuenta que no obtienen una respuesta favorable, optan por ignorarlos y se dedican a realizar ellos solos su trabajo.

Solicitan y buscan diversos tipos de apoyo. Como se observa en la tabla 1, las dos primeras estrategias involucran principalmente a colegas y padres de familia. A estos últimos se les informa periódicamente sobre los comportamientos de sus hijos para que refuercen ciertas habilidades y actitudes en casa.

Cuando se trata de niños "muy inquietos" o que requieren una atención especializada, las docentes les piden a sus progenitores (papás o mamás) que asistan a la escuela a trabajar determinado tiempo con sus hijos. Esta medida dicen que no ha funcionado del todo porque las madres de familia en ocasiones asisten con desagrado y no apoyan para que los niños se integren; en otras ocasiones, de plano no asisten justificándose con la falta de tiempo. También se da el caso en que la mamá trabaja y le es imposible acudir.

Consultan y solicitan apoyo a compañeras docentes. Con sus colegas intercambian puntos de vista y retoman estrategias que otras han empleado frente a casos similares.

Yo estoy más a favor de la práctica. Esta parte de la cuestión del colegiado me ha dado tal vez más herramientas que incluso un curso. Sí, porque la experiencia de otras compañeras te ayuda a resolver algo que a lo mejor por unas situaciones te conviene más en ese momento (A2014E\#5).

Entre las estrategias que han aprendido y retomado de sus colegas mencionan las siguientes: 
"Las fichas de participación en las asambleas". Antes de comenzar la Asamblea, se le entrega a cada nińo y nińa una ficha para intervenir en el tema que se esté tratando. La condición clave para participar es estar atento a lo que dicen sus compañeros; quien no conserva un buen comportamiento se queda con su ficha y solo puede hacer uso de ella hasta el siguiente día.

"La estrellita de la atención y la escucha". Se otorga como premio por mantenerse disciplinado y atender las indicaciones dadas.

"Encender y apagar la luz del aula". Se emplea para llamar su atención y que escuchen a la docente.

\subsection{Estrategias de atención especializada y psicológica}

Solicitan y buscan apoyo de especialistas. En este punto, aparecen dos instituciones. El Centro de Apoyo Psicopedagógico de Educación Preescolar (CAPEP) ${ }^{5}$, ahora Unidad de Educación Especial y Educación Inclusiva (UDEEI) que pertenece a la Administración Federal de Servicios Educativos del Distrito Federal. Cuando la especialista considera que en ciertos casos se requiere un tratamiento especializado canaliza al niño a la Clínica de la Conducta ${ }^{6}$.

También lo canalizamos a la clínica de la conducta [...] el nińo va en ese proceso, de poder relacionarse de manera pacífica con los niños, ya reconoce, por ejemplo, cuando pega reconoce que es su error, y es capaz de pedir una disculpa, y de atender al niño al que agrede o sea, es una cosa bastante importante porque bueno a él no le importaba, lastimaba, o agredía, no tenía ningún remordimiento, y ahora sí se manifiesta con un poco más de atención a sus compañeros (P2014E\#5).

Cabe señalar que, es el personal especializado de estos centros quien, con base en los reportes de las docentes, sugiere actividades específicas para atender el proceso de desarrollo y aprendizaje de algunos niños. En este sentido, el informe se convierte en un documento clave para dar seguimiento a los casos reportados. Este procedimiento se debe a que son las educadoras quienes coti-

\footnotetext{
5 Todavía en el año 2014 las educadoras manejaban esta denominación, sin embargo, los servicios que antes brindaba esta instancia actualmente forman parte de la Unidad de Educación Especial y Educación Integral (UDEEI). En ella se atiende a niños que enfrentan barreras para el aprendizaje y la participación, en cada plantel de educación básica normativamente debe existir un equipo integrado por la maestra especialista, un psicólogo y un trabajador social. De acuerdo con las docentes consultadas, casi en ningún plantel está el equipo completo.

6 Esta clínica aparece en el directorio de la Administración Federal de Servicios Educativos en el Distrito Federal como parte de las instituciones de atención especializadas en problemas de conducta, atención a victimas y atención de adicciones, avaladas por la Secretaría de Educación Pública <https://www2.sepdf.gob.mx/convivencia/madres_padres/archivos/directorio.pdf>.
} 
dianamente están con los niños y aunque las especialistas se encuentran toda la semana en la escuela estas deben calendarizar las visitas por salón. Aquí, aparecen nuevamente las dificultades para brindar atención personalizada y seguir las recomendaciones del personal de UDEEI ${ }^{7}$.

[...] Por ejemplo con la chiquita me dice la maestra de CAPEP pues siéntate con ella. Entonces, ¿ ¿me siento con ella y descuido a los otros diecinueve? Es difícil, para mí es difícil porque se viene abajo todo el trabajo porque con los demás empezamos reglamento y el respeto y no empujo, evito las groserías entonces es difícil. (A2014E\#3).

De acuerdo con las docentes la canalización de ciertos niños a la Clínica de la Conducta, muchas veces resulta benéfico porque propicia algunos cambios en su entorno familiar o en las actitudes de algún miembro de la misma que resulta ser clave en el desarrollo de los preescolares. Esto en parte se debe a la diversidad de servicios que ofrece la institución, entre ellos:

Ofrecen talleres de trastorno por déficit de atención con / o sin hiperactividad, grupo infantil natural, grupo de análisis de padres, terapia cognitivo-conductual, padres eficaces en entrenamiento sistemático, atención pedagógica, estrategias para estimular el aprendizaje, diagnóstico psicológico, talleres para maestros de educación preescolar, primaria y secundaria, terapia grupal para adolescentes y padres (P2015E\#4).

En resumen, todas estas estrategias aparecen de modo recurrente y, con algunas variantes, son las que comúnmente se utilizan en los jardines de nińos donde laboran quienes fueron entrevistadas. Las docentes las consideran fundamentales en su trabajo debido a la disminución de violaciones a las normas y advierten que su empleo de modo consistente y sistemático llega a producir algunos cambios en los nińos a mediano o largo plazo.

A pesar de identificar logros en el aprendizaje de los niños, las docentes, también advierten la necesidad de recibir, como parte de su formación en servicio, apoyos concretos de parte de la Secretaría de Educación Pública para afrontar con mayor efectividad los problemas cotidianos que surgen en el aula y se han venido complejizando en el tiempo.

\footnotetext{
7 Aunque la docente menciona a CAPEP, actualmente el nombre se ha modificado.
} 


\section{Discusión De los Resultados}

A modo de reflexión final y discusión de los resultados, vale la pena detenerse en analizar los modos de intervención prevalecientes y el enfoque educativo que orienta las estrategias docentes ya señaladas.

Resulta notable la diversidad de estrategias que implementan las entrevistadas; tanto en las estrategias de contención como en algunas del segundo tipo denominado estrategias pedagógicas está presente la pretensión de modelar una conducta esperada vía la experimentación de situaciones indeseables para los niños; como el cambio de lugar o el distanciamiento del grupo y, en situaciones más graves, mediante la incorporación a otro grupo. En este sentido, aparece un reforzamiento centrado en experiencias que se viven como negativas y si esta práctica logra generar un cambio, muy probablemente se basará en el temor a la sanción o en evitar contradecir a la autoridad; lo cual se orienta hacia un enfoque centrado en la obediencia (Curwin et al., 2008). Pero también aparecen estrategias que podrían ubicarse de acuerdo con Latapí (2003) en un enfoque reflexivo dialógico, el cual parte de la concepción evolutiva del desarrollo moral. Desde esta lógica, la intervención pedagógica se centra en brindar oportunidades para que nińos y niñas desarrollen su autonomía moral, se apropien de manera paulatina de ciertas normas y valores, y aprendan a ejercer su libertad con responsabilidad. $\mathrm{Al}$ respecto, este autor basado en la aportación de la teoría del desarrollo del juicio moral de Kohlberg (Power, Higgins \& Kohlberg, 1989) señala: «El ser humano transita por diversos estadios en la formación de sus juicios morales; si la educación ignora el nivel de desarrollo moral del niño y el joven podrá generar una imitación mecánica de las conductas morales, pero no desarrollará una verdadera conciencia ética» (pp. 139-140).

Por otra parte, de acuerdo con las finalidades del Campo formativo. Desarrollo personal y social del Programa de Estudios de educación básica (SEP, 2011), la educación preescolar debe promover dos aspectos relacionados con los procesos de desarrollo infantil: Identidad personal y Relaciones interpersonales. Las competencias y los aprendizajes que se pretende favorecer en las niñas y los niños en cada uno son: 
Tabla 4. Competencias y aprendizajes a potenciar en los niños y en las nińas

\begin{tabular}{ll}
\hline \multicolumn{1}{c}{ Identidad personal } & \multicolumn{1}{c}{ Relaciones interpersonales } \\
\hline $\begin{array}{l}\text { Reconoce sus cualidades y capacidades } \\
\text { y desarrolla su sensibilidad hacia las } \\
\text { cualidades y necesidades de otros. }\end{array}$ & $\begin{array}{l}\text { Acepta a sus compañeras y compañeros como } \\
\text { son, y comprende que todos tienen respon- } \\
\text { sabilidades y los mismos derechos, los ejerce } \\
\text { en su vida cotidiana y manifiesta sus ideas } \\
\text { cuando percibe que no son respetados. }\end{array}$ \\
$\begin{array}{l}\text { Actúa gradualmente con mayor } \\
\text { confianza y control de acuerdo con } \\
\text { criterios, reglas y convenciones exter- } \\
\text { nas que regulan su conducta en los } \\
\text { diferentes ámbitos en que participa. }\end{array}$ & $\begin{array}{l}\text { Establece relaciones positivas con otros, } \\
\text { basadas en el entendimiento, la aceptación, y }\end{array}$ \\
\hline
\end{tabular}

Fuente: SEP (2011, p. 77).

Cabe señalar que las estrategias sistematizadas en este artículo están íntimamente relacionadas con el segundo aspecto correspondiente a identidad personal. Este hallazgo obliga a una mayor profundización en el nivel de educación preescolar para identificar las razones por las que los otros componentes no están suficientemente explicitados, al menos en las narraciones de las catorce docentes entrevistadas. En una etapa posterior será necesario averiguar, con otras técnicas de acercamiento al aula, cuáles son las estrategias que más se emplean y concretamente ¿qué aprenden los niños de las experiencias derivadas de estas estrategias?

\section{¿Qué significados de convivencia emergen de las narrativas docentes?}

Los retos y problemáticas señaladas por las educadoras, de alguna manera, guardan relación con los significados que le atribuyen a la convivencia. $\mathrm{Al}$ respecto se identifican tres elementos.

1. La disciplina como elemento central para el desarrollo de las actividades en el aula, así como un componente inseparable de la convivencia, de ahí que se ponga el acento en quienes exhiben un "mal comportamiento" y en la regulación de la conducta. Algunos autores cuestionan la homologación de disciplina y convivencia (Furlan, 2003), no obstante, para las educadoras resulta difícil desvincularla por formar parte del proceso de socialización en estas edades ${ }^{8}$. Desde su perspectiva, niños y niñas

8 Cabe recordar que en este nivel se atiende a niños de 3 a 5 años con once meses de edad (http://www2.sepdf.gob.mx/que_hacemos/preescolar.jsp). 
deben aprender a regular su conducta y apegarse a las reglas establecidas en el aula. Es necesario conocer cuáles son las normas más importantes para las educadoras y qué tipo de participación tienen los niños en su construcción; porque es insuficiente aspirar a que los niños sigan las reglas del salón si no están basadas en principios democráticos o inspirados en la dimensión ética de los derechos humanos, y si los métodos de aprendizaje impiden la autonomía moral en etapas posteriores.

2. La convivencia parece asociarse a la conservación permanente de un estado de armonía. En este sentido, en la cultura escolar tiene una alta valoración permanecer en silencio, sentado y evitar situaciones de disrupción en el aula. No obstante, aprender a vivir juntos implica el reconocimiento de tensiones en la vida diaria por la diversidad de intereses y necesidades que confluyen en un espacio compartido y más aun en el nivel de educación preescolar, por tratarse de una nueva experiencia de socialización para la población infantil.

Es la institución escolar, donde niños y niñas se enfrentan, desempeñando por primera vez en sus vidas un rol diferente al que tienen en sus hogares. Como lo indica el Programa de Educación Preescolar:

la experiencia de socialización que se favorece en la educación preescolar les implica iniciarse en la formación de dos rasgos constitutivos de identidad que no estaban presentes en su vida familiar: su papel como alumnos; es decir, su participación para aprender de una actividad sistemática, sujeta a formas de organización y reglas interpersonales que demandan nuevas formas de comportamiento, y como miembros de un grupo de pares que tienen estatus equivalente, pero que son diferentes entre sí, sin un vínculo previo y al que une la experiencia común del proceso educativo y la relación compartida con otros adultos, entre quienes la educadora representa una nueva figura de gran influencia para las niñas y los niños (SEP, 2011, pp. 75-76).

Esta realidad pone de relieve la necesidad de establecer criterios o normas que protejan las libertades fundamentales de todos y todas y regulen la actuación individual para asegurar el respeto a los derechos de terceros; sean autoridades escolares, docentes, padres y madres de familia, niños, niñas o adolescentes. Aunque también resulta indispensable aceptar que el reto de aprender a vivir juntos implica reconocer la diversidad de conflictos que se presentan y que estos pueden afrontarse por vías pacíficas, mediante la cooperación y negociación. Es decir, la finalidad de la escuela es que sus integrantes desarrollen capacidades para resolver las tensiones sin violencia. 
Desde esta perspectiva, se asume al conflicto como algo inherente al desarrollo humano y la vida social. Cascón $(2001$, p. 3) señala que frecuentemente, se le otorga un sentido negativo al conflicto y "lo relacionamos con la forma en la que habitualmente hemos visto que se suelen enfrentar o resolver: la violencia, la anulación o destrucción de una de las partes y no, una solución justa y mutuamente satisfactoria”.

Por último, de acuerdo con el tipo de intervención prevaleciente en varios casos, da la impresión de que la responsabilidad para solucionar el problema es depositada en el protagonista de los actos de disrupción e indisciplina. El énfasis puesto en el alumno deriva en una tendencia a reducir la complejidad de la problemática a un asunto con explicación e intervención psicológica. $\mathrm{Al}$ respecto sorprende que se recurra a diagnósticos individuales de los niños y no se aluda a las transformaciones necesarias de la cultura escolar; tampoco se preguntan las educadoras si sus prácticas de enseñanza y modos de ejercer la autoridad tienen alguna influencia en la dinámica del grupo.

Esta primera exploración nos ha permitido asomarnos a la complejidad de asuntos que atraviesan la práctica docente, sistematizar las estrategias educativas empleadas, y preguntarnos si están siendo oportunas y dando los resultados esperados para que nińos y nińas aprendan a regular su conducta y convivir con sus compañeros de grupo.

\section{REFERENCIAS BIBLIOGRÁFICAS}

Bickmore, K. (2004). Discipline for democracy?” School districts management of conflict and social exclusion. Theory and Research in Social Education, 32(1), 75-97. https://doi.org/10.1080/00933104.2004.10473244

Cascón, P. (2001). Educar en y para el conflicto. Barcelona, España: Universidad Autónoma de Barcelona.Recuperado de http://unesdoc.unesco.org/ images/0013/001329/132945s.pdf

Coffey, A. \& Atkinson, P. (2003). Encontrar el sentido a los datos. Estrategias complementarias de investigación. Medellín, Colombia: Editorial Universidad de Antioquia.

Cortina, A. (1996). El quehacer ético. Guía para la educación moral. Madrid: AULA XXI-Santillana.

Curwin, R., Mendler, A. \& Mendler, B. (2008). Discipline with dignity. Alexandria, VA: Association for Supervision and Curriculum Development (ASCD).

Delors, J. (1996). La educación encierra un tesoro. Informe a la UNESCO de la Comisión internacional sobre la educación para el siglo XXI. Madrid, España: Santillana/UNESCO 
Fierro, C. (octubre-diciembre, 2005). El problema de la indisciplina desde la perspectiva de la gestión directiva en escuelas públicas del nivel básico. Revista Mexicana de Investigación Educativa, 10 (27), 1133-1148.

Fierro, C. \& Carbajal, P. (2003). Mirar la práctica docente desde los valores. México: Gedisa.

Fierro, C. \& Fortoul, B. (2011). Escuelas que construyen contextos para el aprendizaje y la convivencia democrática. En XI Congreso Nacional de Investigación Educativa / 17. Convivencia, Disciplina y Violencia en las Escuelas / Ponencia. Recuperado de:

Fierro, C. \& Lizardi, A. (2013). Investigaciones nacionales sobre convivencia escolar. En A. Furlán y T. Spitzer (coords.), Convivencia, disciplina y violencia en las escuelas 2002-2011 (pp. 87-95). México: COMIE-ANUIES.

Fierro, C. \& Tapia, G. (2013). Hacia un concepto de convivencia escolar. En A. Furlán y T. Spitzer (coords.), Convivencia, disciplina y violencia en las escuelas 2002-2012 (pp. 71-86). México: ANUIES/COMIE.

Fierro, C., Carbajal, P. y Martínez-Parente, R. (2010). Ojos que sí ven. Casos para reflexionar sobre la convivencia en la escuela. México: Editorial SM.

Furlan, A. (2003). Introducción. En J. Pińa, A. Furlan y L. Sańudo (coords.), Acciones, actores y prácticas educativas. La investigación educativa en México 1992-2002 (pp. 245-258). México: COMIE.

García, S. \& Vanella, L. (1997). Normas y valores en el salón de clases. México: Siglo XXI-UNAM.

Hirmas, C. \& Eroles, D. (coords) (2008). Convivencia democrática, inclusión y cultura de paz: Lecciones desde la práctica educativa innovadora en América Latina. Chile: Oficina Regional de Educación de la Unesco para América Latina y el Caribe.

http://www.comie.org.mx/congreso/memoriaelectronica/v11/docs/ area_17/2346.pdf

http://www.curriculobasica.sep.gob.mx/index.php/prog-preescolar1/ prog-est-prees-programa

http://www.reformapreescolar.sep.gob.mx/ACTUALIZACION/ PROGRAMA/Preescolar2011.pdf

Power, F. C., Higgins, A \& Kohlberg, L. (1989). Lawrence Kohlberg's Approach to Moral Education. Nueva York, NY: Columbia University Press.

Landeros, L. \& Chávez, C. (2015). Convivencia y disciplina en la escuela. Análisis de reglamentos escolares de México. México: INEE.

Latapí, P. (2003). El debate sobre los valores en la escuela mexicana. México: FCE. 
Monereo, C. (coord.) (1994). Estrategias de enseñanza y aprendizaje. Barcelona, España: Graó.

Perales, C., Arias, E. \& Bazdresch, M. (2014). Desarrollo socioafectivo y convivencia escolar. México: InstitutoTecnológico y de Estudios Superiores de Occidente (ITESO).

Pereda, A., Plá, S. \& Osorio, E. (2013). Disciplina e indisciplina en la escuela. Un estado del conocimiento. En A. Furlán \& T. Spitzer (coords.), Convivencia, disciplina y violencia en las escuelas 2002-2011 (pp. 133-181). México: COMIE-ANUIES.

Popkewitz, T. (1988). Los paradigmas en la ciencia de la educación: sus significados y la finalidad de la teoría. En Paradigma e ideología en investigación educativa. Las funciones sociales del intelectual. Madrid: Mondadori.

Secretaría de Educación Pública (2011). Programa de estudio de Educación Preescolar. Guía para la educadora. México: SEP. Recuperado de: http://www.curriculobasica.sep.gob.mx/index.php/prog-preescolar1/prog-est-prees-programa http://www.reformapreescolar.sep.gob.mx/ACTUALIZACION/ PROGRAMA/Preescolar2011.pdf

Rodríguez Gómez, G. (1999). Metodología de la investigación cualitativa. Archidona, Málaga: Aljibe.

Taylor, S. J. \& Bogdan R. (1987). Introducción a los métodos cualitativos de investigación. Barcelona, España: Paidós.

Tomasevski, K. (Julio-diciembre, 2004). Indicadores del derecho a la educación. Revista Instituto Interamericano de Derechos Humanos, (40), 341-388. Recuperado de http://www.juridicas.unam.mx/publica/librev/rev/iidh/ cont/40/pr/pr18.pdf

Yurén, T. (2005). Ethos y autoformación en los dispositivos de formación de docentes. En T. Yurén, C. Navia y C. Saenger (coords.), Ethos y autoformación del docente. Análisis de los dispositivos de formación de profesores (pp. 19-45). México: Ediciones Pomares.

Zurita, Ú. (2011). Análisis de las propuestas legislativas en torno a la violencia en las escuelas mexicanas: Una mirada crítica. En T. Serrano y A. Ortiz Lazcano (coords.), La investigación social en México 2011, tomo III (pp. 918-930). México: Universidad Autónoma del Estado de Hidalgo.

Zurita, Ú. (2013). Paradojas y dilemas de la participación social en la educación básica en México. Apuntes, 40(72), 85-115. https://doi.org/10.21678/ apuntes.72.676 